Article

\title{
Health Risk Perception, Consumption Intention, and Willingness to Pay for Pig Products Obtained by Immunocastration
}

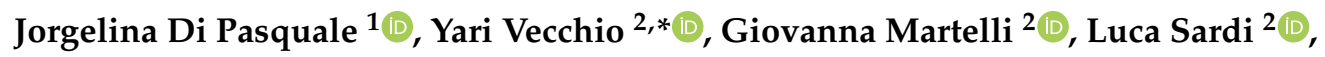 \\ Felice Adinolfi ${ }^{2}$ and Eleonora Nannoni ${ }^{2}$ (D) \\ 1 Faculty of Veterinary Medicine, University of Teramo, 64100 Piano D'Accio, Teramo, Italy; \\ jdipasquale@unite.it \\ 2 Department of Veterinary Medical Sciences, University of Bologna, Via Tolara di Sopra 50, \\ 40064 Ozzano Emilia (Bologna), Italy; giovanna.martelli@unibo.it (G.M.); luca.sardi@unibo.it (L.S.); \\ felice.adinolfi@unibo.it (F.A.); eleonora.nannoni2@unibo.it (E.N.) \\ * Correspondence: yari.vecchio@unibo.it
}

Received: 7 August 2020; Accepted: 26 August 2020; Published: 1 September 2020

check for updates

Simple Summary: Public awareness of farm animal welfare has gradually increased. It is well-known that some routine procedures in pig farming are detrimental to animal welfare, including surgical castration, especially without anaesthesia and/or analgesia. Some alternative techniques that offer welfare advantages over surgical castration can be implemented-immunocastration is among them. However, producers fear that consumers may be frightened by this technique and therefore they delay changes in the production system. This work aimed to understand whether Italian consumers perceive a health risk from the immunocastration technique and whether this perception is connected with their willingness to consume and to pay for products derived from immunocastrated animals. The results show that, within the Italian population, there are different levels of perceived health risk and that, as the perception of risk increases, the willingness to consume products obtained from immunocastrated animals decreases (and vice versa). The health risk perception by consumers also changes the willingness to pay for immunocastrated products. Particular attention must be paid to the information transmitted to the consumer if this technology will be widely adopted in pig husbandry.

\begin{abstract}
Surgical castration without the use of anaesthesia and/or analgesia is considered to be detrimental for the welfare of pigs and for this reason its abandonment is advocated. Immunocastration is a more welfare-friendly alternative method; however, stakeholders in the pork sector fear consumer rejection due to perceived safety issues of immunocastrated meat. This work aimed to analyse whether Italian consumers perceive a health risk arising from the use of this technique and, if so, how the perceived risk may influence the purchase choices and the willingness to pay for products derived from immunocastrated animals. To achieve this objective, a survey was carried out on a representative sample of the Italian population. The results highlight that consumers perceive different levels of risk related to the use of immunocastration and that this influences purchasing behaviour and willingness to pay. Moreover, it should be noted that the willingness to pay is also influenced by certain demographic factors, since this is positively associated with younger respondents with lower incomes and less knowledge of farming systems, who live in rural areas and have a greater sensitivity to animal welfare. Given the concerns expressed by consumers, particular attention must be paid to the information transmitted if this technology will be widely implemented in pig husbandry.
\end{abstract}

Keywords: animal welfare; consumer behaviour; risk perception; willingness to pay; pig; castration; immunocastration; vaccination; alternative methods; consumption 


\section{Introduction}

Several reasons determined the adoption of castration in pig breeding [1]. In addition to reasons related to animal management, such as reducing aggression and sexual behavior [2], the most relevant motivation was the need to reduce the boar taint in the meat of entire male pigs [3]. In these animals, androstenone and skatole accumulate in fat tissues and create a smell and a taste commonly referred to as "boar taint", which are not appreciated by consumers $[4,5]$. However, not all consumers have the same sensitivity to the two molecules. Skatole is perceived by almost all consumers (99\%) [6], while androstenone is perceived by about half of them (40-50\%) [7-10]. Moreover, some studies show that there is a difference in sensitivity related to gender, with women being more sensitive to the presence of androstenone than men [7,9,11-13].

The technique most widely used in Europe to avoid boar taint is castration without the use of anaesthesia and analgesia [14]. This kind of castration can be carried out in accordance with the legislation within seven days of life [15]. The increased sensitivity of European consumers towards the welfare of farm animals has led to a desire to abandon this practice and to adopt alternative techniques, as reported in the European Declaration on alternatives to the surgical castration of pigs [16].

Some countries, such as Spain and the United Kingdom, have chosen to breed entire males, other countries have adopted surgical castration with the use of anaesthesia and analgesia, or have implemented the use of immunocastration. In other contexts, the operators of the pig supply chain try to reduce boar taint risk through nutritional strategies and genetic selection $[14,17-19]$.

Each of these techniques has pros and cons that must be taken into account within each production system [18-22]. In addition to the economic and business management factors related to the introduction of a new production technique, one additional aspect to be taken into consideration is consumer acceptability. Several studies have investigated consumers' ability to accept boar taint $[7,9,12,23,24]$ and the possibility of masking this smell through different food preparation methods [25-28]. Other studies have focused their attention on consumers' acceptability of immunocastration applied in order to improve animal welfare [29-36], but few studies have analysed the perception of risk tied to the application of immunocastration by consumers and the relative willingness to accept this technique, aspects which are fundamental to its implementation [37-40]. Assuming that few consumers are aware that male piglets are surgically castrated without anaesthesia or analgesia, as highlighted in a recent review by Mancini et al. [41], and that few consumers are familiar with the immunocastration technique, it is important to understand their attitude once they are made aware of its possible use, so as not to run into an ancestral rejection of the unknown. According to Claude Fischler's theory [42], men lead their controversial existence between two poles, that of the fear of contamination (neophobia) and that of the tension towards change and diversification (neophilia). Obviously, since the knowledge of foods derives from experience, humans expose themselves to risk at every intake of a new food. Many studies analyzed the perception of risk by consumers. This branch of literature has its roots in the perceived risk theory, initially used in marketing to understand consumer behaviour when making purchasing decisions with imperfect information ([43-52] among others). As regards products of animal origin, other studies addressed the risks associated with the presence of chemical and biological contaminants [53-56], or the use of biotechnologies [57,58], as well as meat consumption and focus, for example, on the consumption of chicken meat [59-62], red meat [63-66], and pork [67-70].

The multiple food scandals of the last twenty years (BSE Bovine Spongiform Encephalopathy, Avian Influenza, Escherichia coli O104: H4; Melamine milk) have sensitized the public opinion to reject the use of many new technologies in the food sector, such as GMOs (Genetically Modified Organisms) $[57,58]$. These attitudes alarm producers, who fear consumers may reject the use of the immunocastration vaccine $[19,71-73]$.

Therefore, a good understanding of consumers' perceptions and attitudes towards innovations in food products and a good use of innovation are crucial for the successful introduction of novelty [74,75].

For this reason, the purpose of this paper is twofold: on the one hand, to investigate the level of health-related risk perceived by consumers for what concerns immunocastration and, on the other 
hand, to verify the existence of a relationship between perceived health risk and propensity to consume and between perceived risk and willingness to pay (WTP). In particular, our analysis aimed to examine how the perception of risk affects purchasing behaviour by determining a higher or lower propensity to consume products obtained through this technique and to investigate how risk perception affects personal preferences in purchasing products obtained through the use of alternative production techniques. Furthermore, it also intends to identify the main variables that influence WTP and how WTP varies according to purchase preferences.

Our research hypothesis is based on the existence of a significant relationship between the perception of risk and the willingness to consume products obtained from immunocastrated animals. Furthermore, we hypothesize different levels of risk perception within the population, resulting in different propensities to consume, preferences for alternative production techniques, and WTP.

Our research questions are therefore expressed as follows: 1 . What is the relationship between risk perception for the use of immunocastration and the propensity to consume the products thus obtained? 2. What is the relationship between risk perception and the preferences of consumption for products obtained through alternative production techniques? 3 . What factors can influence the WTP for products obtained through immunocastration?

This document aims to contribute to the abundant literature $([41,76,77]$ among others) on the WTP for products with higher animal welfare standards than current ones, trying to fill the knowledge gap on the effect that the perception of risk for immunocastration has on personal preferences.

\section{Materials and Methods}

\subsection{Research Approach and Sampling}

Between December 2018 and January 2019, a representative sample of the Italian population of pork consumers was surveyed. Participation quotas were identified by gender, age (older than 18 years) and geographical area (North-West, North-East, Centre, South, Islands) [78]. The questionnaire was designed by the authors based on a review of the literature available on immunocastration. Subsequently, a pre-test was carried out with 20 volunteers to verify that questions were understandable to readers and that there was no risk of misinterpretation. The questionnaire was slightly modified based on volunteers' feedback. These twenty respondents were not included in the final survey. Afterward, a pilot survey was carried out on a sample of 126 interviewees.

In the questionnaire used for the study, consumers were asked to read a short paragraph containing information about immunocastration, which was previously tested by experts and consumers to ensure it was neutral. Any word that could voluntarily elicit emotions was carefully eliminated from the text, such as "piglets", "pain", or word such as "much" or "little". Likewise, any concept that might reveal a preference by the authors for one technique over another was avoided (the paragraph is provided in the supplementary material Table S1). This step aimed to increase the consumers' knowledge of the investigation topic. The survey was carried out by a specialized agency, with CAWI (Computer Assisted Web Interview) methodology. The response rate was $73 \%$, and $3.8 \%$ of responses were screened-out because respondents were non-consumers of pork. The final sample consisted of 969 Italian respondents. The questions used for the analysis are presented below in the specific sections of the manuscript.

\subsection{Statistical Analysis}

All analyses were conducted with SPSS V.25.0 (IBM Corp., Armonk, NY, USA, Released 2017)

2.2.1. Correlation Analysis to Verify Which Relationship Exists between the Perception of Risk for the Use of Immunocastration and the Propensity to Consume the Products Thus Obtained

In order to assess the relationships between the level of risk perceived by consumers in relation to immunocastration and the propensity to consume products derived from immunocastrated animals, 
a correlation between two variables was tested: the first one capable of gathering information on the willingness to consume products from immunocastrated animals defined as variable 1 "willingness to consume", and the second one suitable for collecting information relating to the perception of risk, defined as variable 2 "risk perception".

"Willingness to consume" is a continuous variable, for which data were collected by means of an open question (asking to express a level on a scale from 0 to 100), submitted to the consumer in the following way: "Assuming that the abandonment of surgical castration and the adoption of immunocastration would improve pig welfare, to what extent would you be willing to consume products obtained through the use of immunocastration? Please rate your score on a 0 to 100 scale".

"Risk perception" is, similar to "willingness to consume", a continuous variable, for which data were collected by means of an open question which was submitted to the consumer in the following way "Please indicate (express it as a percentage) to what extent do you think that immunocastration might carry some risks (even if still unknown) for consumers' health $\% "$.

The correlation between these two variables should indicate whether the increase in the perception of risk relating to foods obtained from animals subjected to immunocastration decreases (or not) the willingness to consume these products. The Pearson correlation coefficient was used to carry out this analysis.

2.2.2. ANOVA Test to Verify the Relationship between the Perception of Risk and the Preferences of Consumption for Products Obtained through Alternative Breeding Techniques

In order to verify how the perception of risk can influence consumers' purchasing choices, the analysis carried out several steps:

Firstly, respondents had to indicate their purchasing preference among the alternative methods to avoid boar taint. Or rather, they were offered the opportunity to choose one among five alternative methodologies found in the literature (Table 1). In this way the sample self-selected into five groups.

Table 1. Alternative methodologies found in the literature to avoid boar taint.

\begin{tabular}{lc}
\hline Please, Indicate Your Purchasing Preference among the Following Pork Products (Single Choice) ${ }^{\mathbf{1 , 2}}$ \\
\hline 1 & From animals surgically castrated \\
2 & From animals surgically castrated with pain relief (anaesthesia/analgesia) \\
3 & From entire animals genetically selected to reduce the levels of boar taint \\
4 & From immunocastrated animals \\
5 & From entire animals (I do not care about boar taint) \\
\hline 1 & Fote: Raising only female animals has also been proposed in the literature. However, sperm sexing is currently
\end{tabular}

${ }^{1}$ Note: Raising only female animals has also been proposed in the literature. However, sperm sexing is currently not perfected enough to make this option viable. For this reason, this technique was not offered among the possible choices, but the possibility of including it in "other" was left in case some consumers were aware of it. No consumer chose the "other" option. ${ }^{2}$ Note: the order of possible choices was randomized.

Subsequently, two one-way ANOVA tests were carried out on the five groups thus obtained. The first one-way ANOVA test was performed to verify whether the level of willingness to consume products obtained from immunocastration was different and statistically significant among the groups of consumers who declared different preferences. The second one-way ANOVA test was performed to check whether the level of the perceived risk for products obtained from immunocastrated pigs was different among the five groups.

The first test used variable 1 "willingness to consume" as its dependent variable, while in the second one, we used variable 2 "risk perception" as the dependent variable.

In order to validate the quality of the analysis, robustness tests were conducted. Based on the characteristics of the variables tested, the Brown and Forsythe [79] and Welch [80] tests were chosen. Moreover, pairwise comparisons were carried out by using Duncan [81] and Scheffe [82] post hoc tests to confirm the absence of significant differences between all possible pairs of averages. Statistical significance was set at $p<0.05$ for all tests. 
2.2.3. WTP-Logit Regression to Verify Which Factors Can Influence the Willingness to Pay for Products Obtained through Immunocastration and Assessment of How the Willingness to Pay Varies according to Purchase Preferences

In order to identify the characteristics that determine the highest probability that an individual is willing to pay a premium price for a food obtained through the use of immunocastration, a logistic regression was carried out on the entire sample representative of the Italian population. Subsequently, within each self-selected group based on the preference for alternative breeding techniques, we assessed the average value that each group of individuals is willing to pay for immunocastrated product.

The logistic regression analysis is mainly used to deal with the choice of a binary scenario [83].

In fact, the independent part is represented by a binary variable to which is linked a random variable $Y_{i}$ with a Bernoullian distribution. It is used above all for its predictive function, with which it is possible to estimate the probability that in an independent data event, $n$ regressors will occur. In the interpretation of the result, the beta parameter, which illustrates the negative or positive effects on the dependent variable by the regressors, must be estimated. In our case we use Wald's test to estimate the existence of a statistically significant relationship. In addition, the results of the maximum probability (ML) algorithm and the R2 values of Cox and Snell and Nagerkelke will be commented on to estimate the goodness of the model $[84,85]$.

In our case, we have selected as a dichotomous dependent variable the willingness to pay a premium price or not for products obtained through the technique of immunocastration. As independent variables, we included all the characteristics identified in the literature as determining factors in the decision to buy products with higher standards of animal welfare.

The variables used are the following (Table 2).

Table 2. List of variables used in logit regression.

\begin{tabular}{ccc}
\hline Code Variable & Label & Modalities ${ }^{\mathbf{1}}$ \\
\hline Gender & Gender & 2 \\
Education & Level of education & 6 \\
Income & Income & 6 \\
Age & Age of respondents & Free \\
Home & Do you live in rural or urban area? & 2 \\
Aware & Are you aware that male pigs are castrated in their & 2 \\
Animal Welfare (AW)-importance & Importance given to animal welfare during purchase & 7 \\
Pig Welfare & Perceived level of pig welfare on farms & 5 \\
Knowledge & Knowledge about AW & 5 \\
\hline
\end{tabular}

${ }^{1}$ Note: The specification of the modalities relating to socio-demographic variables can be viewed in the sample table in Supplementary Materials Table S2.

The logistic model was conducted using the stepwise technique. This technique consists of a method of adaptation of the regression models, in which the predictors are automatically chosen through the use of a predetermined criterion. In our case, we used a stepwise forward technique using Wald's statistic.

In order to identify the average price increase consumers would pay for products derived from immunocastration, the following question was asked: "Which premium price, expressed as a percentage, would you be willing to pay for immunocastrated pork? Please rate your score on a 0 to 100 scale $\% "$.

Subsequently, the average premium price that consumers are willing to pay for products obtained through immunocastration was calculated both for the entire surveyed sample and for each group defined based on the preferred alternative techniques, regardless of their consumption preference. 


\section{Results}

This section is divided by subheadings, in order to provide a more precise description of the experimental results.

3.1. Results of Correlation Analysis to Verify What Type of Relationship Exists between the Perception of Risk for the Use of Immunocastration and the Willingness to Consume the Products Thus Obtained

The correlation analysis based on Pearson's correlation coefficient between the variables 1 "willingness to consume" and 2 "risk perception" for consumers' health indicated a statistically significant correlation, with an inversely proportional weak ratio (Table 3), that is, as the perception of the risk for the health of the consumer increases, the willingness to consume the products obtained through immunocastration decreases.

Table 3. Correlation based on Pearson's correlation coefficient.

\begin{tabular}{ccc}
\hline & \multicolumn{3}{c}{ Correlations } \\
\hline & willingness to consume & risk perception \\
willingness to consume & 1 & $-0.232^{1}$ \\
risk perception & $-0.232^{1}$ & 1 \\
\hline \multicolumn{2}{c}{ Correlation is significant at the 0.01 level (2-tailed). }
\end{tabular}

\subsection{Results of ANOVA Test to Verify the Relationship between the Perception of Risk and the Consumption Preferences for Products Obtained through Alternative Breeding Techniques}

Concerning the methods used to avoid boar taint, consumers have indicated their preference by choosing among the four methods proposed in the literature and the methodology widely in use at present (surgical castration without the use of anaesthetics). The different methodologies have different levels of preference among consumers. The least preferred technique within the population is surgical castration without the use of anaesthesia/analgesia, i.e., the most widespread, which was chosen by only $9.2 \%$ of consumers. This methodology is followed by the choice to breed animals genetically selected for their low risk of developing boar taint, which was preferred by $15.9 \%$ of consumers. The remaining three techniques, surgical castration with the use of anaesthesia/analgesia, breeding of entire animals, and immunocastration, are preferred by a fifth of consumers for the first two and by a third of consumers for the third (Table 4).

Table 4. Consumer preference for one among the alternative methodologies found in the literature to avoid boar taint.

\begin{tabular}{ccc}
\hline Please, Indicate Your Purchasing Preference Among the Following Pork Products (Single Choice) \\
\hline Preferred Alternative Meat Products & Frequency & Percent \\
\hline From animals surgically castrated & 89 & $9.2 \%$ \\
From entire animals genetically selected to reduce the levels of boar taint & 154 & $15.9 \%$ \\
From animals surgically castrated with pain relief & 198 & $20.4 \%$ \\
(anaesthesia/analgesia) & 202 & $20.9 \%$ \\
From entire animals (I do not care about boar taint) & 326 & 33.6 \\
From immunocastrated animals & 969 & $100 \%$ \\
\hline Total & &
\end{tabular}

One-way ANOVA highlighted a different propensity to consume immunocastrated meat among groups, as well as a statistically significant difference in the perception of risk (Table 5). That is, the consumers who indicated their preference for traditional surgical castration are also those who are less willing to consume food products derived from immunocastrated pigs, followed by those who would accept boar taint in meat if entire animals were raised and those who would prefer castration with the use of anaesthesia/analgesia. Consumers who prefer the technique of immunocastration 
and perceive the lowest risk are, of course, more willing to consume these products. A higher risk is perceived by consumers who would prefer traditional castration.

Table 5. One-way ANOVA: Willingness to consume based on different alternative methods to avoid boar taint and risk perception for products obtained from immunocastrated pigs.

\begin{tabular}{|c|c|c|c|c|}
\hline Statistics & Choice (Means) & Frequency & $\begin{array}{l}\text { Willingness to } \\
\text { Consume, } \%\end{array}$ & $\begin{array}{c}\text { Risk Perception, } \\
\%\end{array}$ \\
\hline \multirow{4}{*}{ Mean } & Pork from animals surgically castrated & 89 & 39.56 & 43.97 \\
\hline & $\begin{array}{l}\text { Pork from entire animals (I do not care } \\
\text { about boar taint) }\end{array}$ & 202 & 44.98 & 40.11 \\
\hline & $\begin{array}{l}\text { Pork from animals surgically castrated with } \\
\text { pain relief (anaesthesia/analgesia) }\end{array}$ & 198 & 49.17 & 38.07 \\
\hline & $\begin{array}{l}\text { Pork from animals genetically selected to } \\
\text { reduce the levels of boar taint }\end{array}$ & 154 & 52.21 & 40.08 \\
\hline & Pork from immunocastrated animals & 326 & 68.92 & 22.84 \\
\hline Total & & 969 & 54.54 & 34.23 \\
\hline \multirow{2}{*}{ Anova } & F-test & & 29.276 & 24.293 \\
\hline & $p$-Value & & $<0.001$ & $<0.001$ \\
\hline
\end{tabular}

Similarly, pairwise comparisons show that consumers preferring meat from immunocastrated animals have statistically higher willingness to consume these products and statistically lower perceived risk levels compared to all the other groups of consumers.

On average, consumers indicated a perceived level of risk below 35, which is relatively low since it refers to a $0-100$ scale, and a relatively high (almost $55 \%$ ) willingness to consume products derived from immunocastrated animals (Table 5).

The existence of statistically significant differences between the different groups considered is demonstrated by a highly significant $p$-Value (less than 0.001). Therefore, the five groups can be considered different with regard to their propensity to consume and propensity to risk. The most important differences are between group 1 (traditional surgical castration) and group 5 (immunocastration) (Table 5) both in terms of propensity to consume and risk perception, which can be expected given the negative correlation of the variables tested. This leads us to accept the null hypothesis of equal propensity to consume and perception of risk. The two robustness tests of Welch and Brown-Forsythe (Table 6) were carried out and confirmed the possibility of accepting the null hypothesis since the significance of the test is less than 0.05 .

Table 6. Robust Tests of Equality of Means.

\begin{tabular}{cccc}
\hline Variable & Test & Statistic $^{\mathbf{1}}$ & Sig. \\
\hline \multirow{2}{*}{ Consume } & Welch & 30.383 & 0.000 \\
& Brown-Forsythe & 28.733 & 0.000 \\
Risk & Welch & 28.758 & 0.000 \\
& Brown-Forsythe & 21.914 & 0.000 \\
\hline \multicolumn{4}{c}{ Asymptotic F distribution. }
\end{tabular}

Subsequently, post hoc tests (Duncan and Scheffe; Supplementary Materials Table S3) were performed, which confirmed the presence of statistically significant differences and therefore the presence of heterogeneous subsets for alpha $=0.05$.

\subsection{Results of Logit Regression to Verify Which Factors Can Influence the Willingness to Pay for Products Obtained through Immunocastration}

Assuming the null hypothesis to be true, the model correctly predicts $26.1 \%$ of the observations, but does not consider the presence of the independent variables. Instead, if the model is tested by including the independent variables, the correct percentage increases to $73.9 \%$, thus confirming the alternative one as the best hypothesis. The results of the model are shown in Table 7. 
Table 7. Output and Summary Statistics of the Logit Model.

\begin{tabular}{cccccc}
\hline Variables & B & S.E. & Wald & Sig. & Exp(B) \\
\hline Age & -0.016 & 0.005 & 9.568 & 0.002 & 0.984 \\
Income & -0.19 & 0.065 & 8.477 & 0.004 & 0.827 \\
AW importance & 0.096 & 0.032 & 9.087 & 0.003 & 1.101 \\
Knowledge & -0.216 & 0.061 & 12.382 & 0 & 0.806 \\
Urban or Rural & -0.521 & 0.214 & 5.912 & 0.015 & 0.594 \\
Pig welfare & 0.177 & 0.065 & 7.481 & 0.006 & 1.194 \\
-2 Log likelihood & Cox \& Snell R Square & Nagelkerke R Square & Chi-Square & Df & Sig. \\
1059.361 & 0.254 & 0.339 & 283.958 & 6 & 0.000 \\
\hline
\end{tabular}

If we set the error tolerated at $5 \%(p$-value $=0.05)$ with six degrees of freedom, the value of the statistics of the distribution table is 12.59 . In our case, the Chi square assumes the value of 283.958; therefore, we can reject the null hypothesis, because the value of the chi square obtained from our data turns out to be superior to that shown in Table 5 . This, if we set the error at $5 \%$, therefore represents a good measure of likelihood for our test. A high value of the Cox and Snell R Square and Nagelkerke $\mathrm{R}$ Square indices is a measure of the model's robustness. As shown in Table 5, the Cox and Snell $\mathrm{R}$ Square and Nagelkerke R Square values are 0.254 and 0.339 , respectively. The value of the likelihood-2 logarithm for the search model is 1059.361. Hair et al. [58] suggest that the lower the probability value of the likelihood logarithm, the better the goodness of the search model.

The independent variables included in the model are statistically significant in identifying the consumers willing to pay a premium price. It turns out that people who are consumers living in rural areas and who are younger and have lower incomes are willing to pay a higher share for "immunocastration" products; these two last measures are significantly correlated according to the Pearson correlation index. Furthermore, individuals who value animal welfare but have less knowledge of the subject and who believe that pigs are raised with acceptable minimum standards tend to spend more.

\subsection{Results of WTP and Evaluation on How It Varies according to Purchase Preferences}

Once the variables influencing the WTP of Italian consumers were defined, the WTP intensity for products derived from immunocastration of the five previously identified groups was investigated. The results are presented in Figure 1.

\section{Mean WTP}

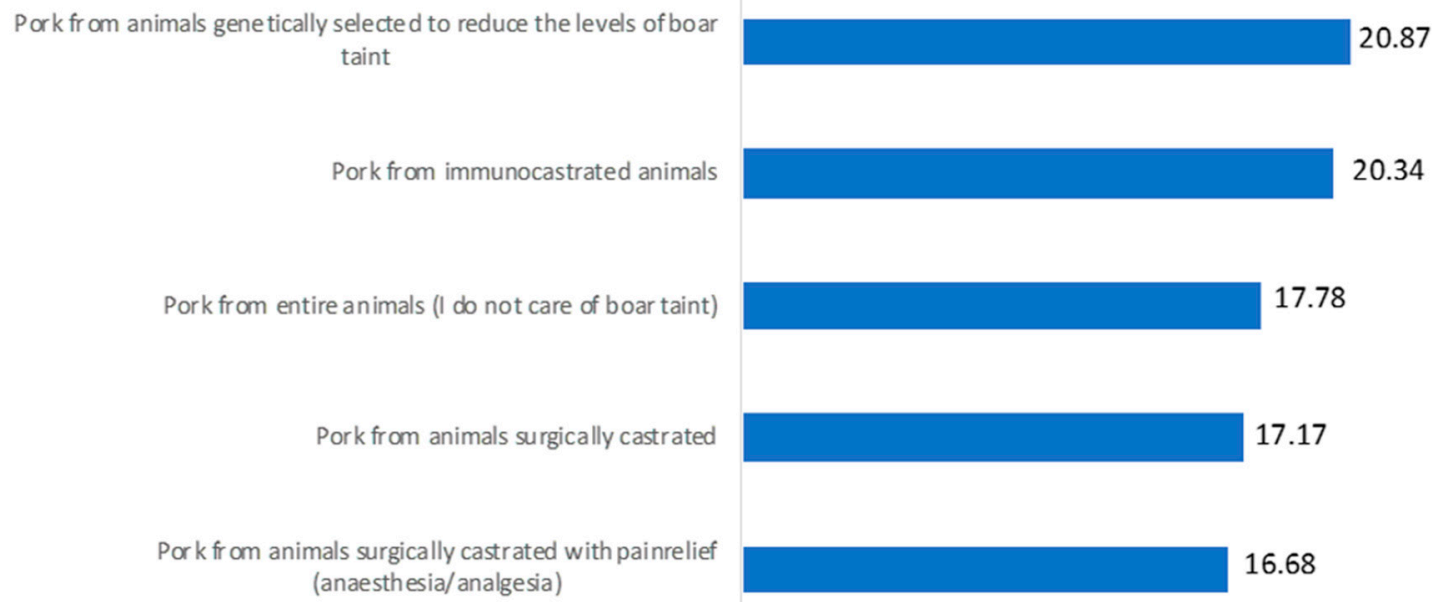

Figure 1. Average percentage increase in WTP $(\%)$ for products derived from the immunocastration based on the five different consumer groups. 
The WTP found in all groups is relatively high. It averages around a price increase of $18.6 \%$ and ranges from a minimum of $+16.68 \%$ to a maximum of $+20.87 \%$. Consumers who prefer products obtained through the use of surgical castration (with or without the use of anaesthetics) are those who declare a lower WTP. Instead, consumers who accept more easily the use of technology in the food sector, such as genetic selection or the use of a vaccine, are willing to pay a higher premium price.

\section{Discussion}

The propensity to consume products obtained through the use of immunocastration goes hand in hand and in an inversely proportional way to the perception of the risk linked to the use of the technique. In fact, the correlation shown between variable 1 and variable 2 indicates a direct, statistically significant, although not excessively strong link. Consumers who believe that eating food from immunocastrated animals implies no health risk are more willing to consume these products. On the contrary, consumers who think immunocastration can pose a health risk and are somewhat frightened by it are less likely to consume these products. This result confirms first of all that Italian consumers perceive a risk in the application of the immunocastration technique, as evidenced by other works $[38,39,60]$. However, the level of perceived risk is on average low. Secondly, it shows different levels of risk perception. Even though about $30 \%$ of consumers prefer to consume meat from animals that have not been pharmacologically treated (products obtained through the use of surgical castration, 9.2\%, and raising entire animals products obtained through the breeding of whole pigs, $20.9 \%)$, the percentage of those who would prefer the use of alternative techniques to avoid the boar smell in meat in favour of animal welfare is extremely high (90.8\%). This result confirms what has already been widely highlighted in the literature $[30,35,39,86,87]$, that is, the surgical castration without the use of anaesthesia/analgesia has been identified by consumers as a technique not respectful of animal welfare and therefore not desirable, and this is the case also for Italian consumers.

It is possible that immunocastration may not be the only technique to be considered in pig farms, since about one fifth of the interviewed sample would prefer castration with the use of anaesthetics and/or analgesics, another fifth would accept the boar taint in meat; $15 \%$ would accept genetic selection of pigs that express this feature to a lower extent. As highlighted by some works [21,41], each of the above-mentioned techniques has managerial and economic constraints that must be taken into due consideration. However, immunocastration remains the technique that received the highest preference (33.6\% of the sample).

Consumers who are more inclined to accept innovative techniques, such as the genetic selection of pigs and immunocastration itself, perceive a lower risk in its use and are more willing to consume the products thus obtained. Consumers who are less inclined to consume products derived from immunocastrated pigs are those who perceive a higher risk linked to the use of the technique. These respondents remain anchored to purchasing and consumption routines, and would continue consuming products obtained with surgical castration (with or without anaesthetics/analgesics), or even to accept the boar taint in meat, products which, for their use history can be traced back to the "precautionary principle". The latter result is in line with the literature, which indicates a greater acceptability of innovation in the food sector when it is configured as incremental innovation, i.e., when the innovation is gradually implemented or when only one attribute of the product is modified $[88,89]$.

The level of perceived risk also has an effect on WTP. The average WTP for products obtained by immunocastration is $18.6 \%$. Nonetheless, consumers who chose products obtained from surgical castration and castration with anaesthesia and/or analgesia, remaining in a "comfort zone", declared a higher WTP, between $16.68 \%$ and $17.78 \%$. Consumers who demonstrate greater openness to new technologies declared a higher WTP, between $20.34 \%$ and $20.87 \%$.

This is a declared willingness to pay and is therefore certainly overestimated, but the data indicate a clear trend which confirms some of the hypotheses of our work. The characteristics that determine the willingness to pay a premium price for products obtained through immunocastration are young age and low income. The two variables are related, since often, in Italian society, young people enter 
the world of work quite late and this determines their economic condition; however, their greater sensitivity towards animal welfare determines a greater propensity to choose foods produced in a more animal-friendly way. The housing environment is also an important determinant of behaviour, and in particular living in a rural context, as is poor knowledge of breeding conditions. This is in contrast to what can be found in the literature, where detachment from rural life determines a greater apprehension for animal welfare $[90,91]$. The other results are in agreement with the literature in which young age, lack of knowledge of the living conditions of animals, and greater sensitivity towards animal welfare influence WTP [76,77,91,92].

\section{Conclusions}

This work highlighted that Italian consumers perceive a human health-related risk tied to the application of immunocastration. However, there are different levels of risk perception within the population, and these differences are reflected in different types of behaviour and food choices about immunocastration. In other words, the existing and statistically significant relationship between the level of risk perceived by consumers and the propensity to consume these foods determines a different preference for alternative boar taint management strategies. Furthermore, a different level of WTP for products derived from immunocastrated animals could be observed according to different purchasing preferences in relation to the different perceptions of risk. These results indicate that the concerns raised by the producers are not unfounded, as consumers perceived certain risks. However, among the proposed alternative techniques, immunocastration was the preferred technique for more than $30 \%$ of the sample, and the overall level of the health-related risk perceived was low (below $35 \%$ ). If immunocastration will be implemented as a standard production technique, it will be necessary to convey more information to the consumer in order to decrease their perception of the health-related risk and avoid the possibility of a refusal of this production technique due to a lack of knowledge.

Supplementary Materials: The following are available online at http://www.mdpi.com/2076-2615/10/9/1548/s1, Table S1: Short, neutral information about immunocastration, Table S2: Socio-demographic variables used in logit regression, Table S3: socio-demographic variables, Output of the post-hoc Scheffe Test $(p<0.05)$.

Author Contributions: Conceptualization, J.D.P.; methodology, J.D.P., Y.V. and F.A.; validation, J.D.P., E.N. and G.M.; software, Y.V.; formal analysis, Y.V., J.D.P. and F.A.; investigation, J.D.P; resources, L.S., G.M.,E.N., F.A.; data curation, J.D.P. and Y.V.; writing-original draft preparation, J.D.P and Y.V.; writing-review and editing, J.D.P., Y.V., F.A., E.N., G.M., and L.S.; visualization, J.D.P., Y.V.; supervision, J.D.P.; project administration, J.D.P.; funding acquisition, L.S. All authors have read and agreed to the published version of the manuscript.

Funding: This research received no external funding.

Acknowledgments: We would like to thank all those who helped us in pre-testing the questionnaire. We would also like to thank the anonymous reviewers for their fundamental support in improving the quality of our manuscript.

Conflicts of Interest: The authors declare no conflict of interest.

\section{References}

1. Zamaratskaia, G.; Rasmussen, M.K. Immunocastration of male pigs-situation today. Procedia Food Sci. 2015, 5, 324-327. [CrossRef]

2. Rydmher, L.; Lundstrom, K.; Andersson, K. Immunocastration reduces aggressive and sexual behavior in male pigs. Animal 2010, 4, 965-972. [CrossRef] [PubMed]

3. Brunius, C.; Zamaratskaia, G.; Andersson, K.; Chen, G.; Norrby, M.; Madej, A.; Lundstrom, K. Early immunocastration of male pigs with Improvac-Effect on boar taint, hormones and reproductive organs. Vaccine 2011, 29, 9514-9520. [CrossRef] [PubMed]

4. Bonneau, M. Compounds responsible for boar taint, with special emphasis on androstenone: A review. Livest. Prod. Sci. 1982, 9, 687-705. [CrossRef]

5. Claus, R.; Weiler, U.; Herzog, A. Physiological aspects of androstenone and skatole formation in the boar-A review with experimental data. Meat Sci. 1994, 38, 289-305. [CrossRef] 
6. Weiler, U.; Fischer, K.; Kemmer, H.; Dobrowolski, A.; Claus, R. Influence of androstenone sensitivity on consumer reactions to boar meat. In Boar Taint in Entire Male Pigs, 92nd ed.; Bonneau, M., Lundström, K., Malmfors, B., Eds.; EAAP: Roma, Italy, 1997; Volume 92, pp. 147-151.

7. Weiler, U.; Font i Furnols, M.; Fischer, K.; Kemmer, H.; Oliver, M.A.; Gispert, M.; Claus, R. Influence of differences in sensitivity of Spanish and German consumers to perceive androstenone on the acceptance of boar meat differing in skatole and androstenone concentrations. Meat Sci. 2000, 54, 297-304. [CrossRef]

8. Font i Furnols, M.; Gispert, M.; Diestre, A.; Oliver, M.A. Acceptability of boar meat by consumers depending on their age, gender, culinary habits, and sensitivity and appreciation of androstenone odour. Meat Sci. 2003, 64, 433-440. [CrossRef]

9. Blanch, M.; Panella-Riera, N.; Chevillon, P.; Font i Furnols, M.; Gil, M.; Gil, J.M.; Oliver, M.A. Impact of consumer's sensitivity to androstenone on acceptability of meat from entire male pigs in three European countries: France, Spain and United Kingdom. Meat Sci. 2012, 90, 572-578. [CrossRef]

10. Razafindrazaka, H.; Monnereau, A.; Razafindrazaka, D.; Tonasso, L.; Schiavinato, S.; Rakotoarisoa, J.-A.; Pierron, D. Genetic admixture and flavor preferences: Androstenone sensitivity in Malagasy populations. Hum. Biol. 2015, 87, 59-70. [CrossRef]

11. Bremner, E.A.; Mainland, J.D.; Khan, R.M.; Sobel, N. The prevalence of androstenone anosmia. Chem. Sen. 2003, 28, 423-432. [CrossRef]

12. Lunde, K.; Skuterud, E.; Nilsen, A.; Egelandsdal, B. A new method for differentiating the androstenone sensitivity among consumers. Food Qual. Prefer. 2009, 20, 304-311. [CrossRef]

13. Wysocki, C.J.; Beauchamp, G.K. Ability to smell androstenone is genetically determined. Proc. Natl. Acad. Sci. USA 1984, 81, 4899-4902. [CrossRef] [PubMed]

14. Backus, G.; Higuera, M.; Juul, N.; Nalon, E.; De Briyne, N. Second Progress Report 2015-2017 on the European Declaration on Alternatives to Surgical Castration of Pigs. Available online: https://www.boarsontheway. com/wp-content/uploads/2018/08/Second-progress-report-2015-2017-final-1.pdf (accessed on 20 July 2020).

15. Council Directive 2008/120/EC of 18 December 2008 Laying Down Minimum Standards for the Protection of Pigs (Codified Version) ELI. Available online: http://data.europa.eu/eli/dir/2008/120/oj (accessed on 20 July 2020).

16. European Declaration on Alternatives to Surgical Castration of Pigs. Available online: https://ec.Europa.eu/ food/sites/food/files/animals/docs/aw_prac_farm_pigs_cast-alt_declaration_en.pdf (accessed on 20 July 2020).

17. De Briyne, N.; Berg, C.; Blaha, T.; Temple, D. Pig castration: Will the EU manage to ban pig castration by 2018? Porcine Health Manag. 2016, 2, 29. [CrossRef] [PubMed]

18. Bonneau, M.; Weiler, U. Pros and Cons of Alternatives to Piglet Castration: Welfare, Boar Taint, and Other Meat Quality Traits. Animals 2019, 9, 884. [CrossRef] [PubMed]

19. European Commision-Establishing Best Practices on the Production, the Processing and the Marketing of Meat from Uncastrated Pigs or Pigs Vaccinated Against Boar Taint (Immunocastrated)—Final Report. Available online: https://ec.europa.eu/food/sites/food/files/animals/docs/aw_prac_farm_pigs_cast-alt_establishingbest-practices.pdf (accessed on 20 July 2020). [CrossRef]

20. Kress, K.; Verhaagh, M. The Economic Impact of German Pig Carcass Pricing Systems and Risk Scenarios for Boar Taint on the Profitability of Pork Production with Immunocastrates and Boars. Agriculture 2019, 9, 204. [CrossRef]

21. Kress, K.; Millet, S.; Labussière, E.; Weiler, U.; Stefanski, V. Sustainability of Pork Production with Immunocastration in Europe. Sustainability 2019, 11, 3335. [CrossRef]

22. Kress, K.; Weiler, U.; Schmucker, S.; Čandek-Potokar, M.; Vrecl, M.; Fazarinc, G.; Škrlep, M.; Batorek-Lukač, N.; Stefanski, V. Influence of Housing Conditions on Reliability of Immunocastration and Consequences for Growth Performance of Male Pigs. Animals 2020, 10, 27. [CrossRef]

23. Malmfors, B.; Lundström, K. Consumer Reactions to Boar Meat-A Review. Livest. Prod. Sci. 1983, 10, 187-196. [CrossRef]

24. Font-i-Furnols, M. Consumer studies on sensory acceptability of boar taint: A review. Meat Sci. 2012, 92, 319-329. [CrossRef]

25. Stolzenbach, S.; Lindahl, G.; Lundström, K.; Chen, G.; Byrne, D.V. Perceptual masking of boar taint in Swedish fermented sausages. Meat Sci. 2009, 81, 580-588. [CrossRef]

26. Martínez, B.; Rubio, B.; Viera, C.; Linares, M.B.; Egea, M.; Panella-Riera, N.; Garrido, M.D. Evaluation of different strategies to mask boar taint in cooked sausage. Meat Sci. 2016, 116, 26-33. [CrossRef] [PubMed] 
27. Meier-Dinkel, L.; Gertheiss, J.; Schnäckel, W.; Mörlein, D. Consumer' perception and acceptance of boiled and fermented sausages from strongly boar tainted meat. Meat Sci. 2016, 118, 34-42. [CrossRef] [PubMed]

28. Borrisser-Pairó, F.; Panella-Riera, N.; Gil, M.; Kallas, Z.; Linares, M.B.; Egea, M.; Garrido, M.D.; Oliver., M.A. Consumers' sensitivity to androstenone and the evaluation of different cooking methods to mask boar taint. Meat Sci. 2017, 123, 198-204.

29. Hennessy, D.; Newbold, R. Consumer attitudes to boar taint and immunocastration: A qualitative study. In Proceedings of the 18th International Pig Veterinary Society, Hamburg, Germany, 27 June-1 July 2004.

30. Lagerkvist, C.; Carlsson, F.; Viske, D. Swedish consumer preferences for animal welfare and biotech: A choice experiment. AgBioforum 2006, 9, 51-58.

31. Allison, J.; Wright, N.; Martin, S.; Wilde, N.; Izumi, E. Consumer acceptance of the use of vaccination to control boar taint. In Proceedings of the 59th Annual Meeting of the European Association of Animal Production, Vilnius, Lithuania, 24-27 August 2008.

32. Giffin, B.J.; Allison, J.R.D.; Martin, S.; Ward, P.; Tschopp, A. Consumer acceptance of the use of vaccination to control boar taint. In Proceedings of the 20th International Pig Veterinary Society Congress, Durban, South Africa, 22-26 June 2008.

33. Vanhonacker, F.; Verbeke, W.; Tuyttens, F.A.M. Belgian consumers' attitude towards surgical castration and immunocastration of piglets. Anim. Welf. 2009, 18, 371-380.

34. Tuyttens, F.A.M.; Vanhonacker, F.; Langendries, K.; Aluwè, M.; Millet, S.; Bekaert, K.; Verbeke, W. Effect of information provisioning on attitude toward surgical castration of male piglets and alternative strategies for avoiding boar taint. Res. Vet. Sci. 2011, 91, 327-332. [CrossRef] [PubMed]

35. Vanhonacker, F; Verbeke, W. Consumer response to the possible use of a vaccine method to control boar taint v. physical piglet castration with anaesthesia: A quantitative study in four european countries. Animal 2011, 5, 1107-1118. [CrossRef]

36. Sødring, M.; Nafstad, O.; Håseth, T.T. Change in Norwegian consumer attitudes towards piglet castration: Increased emphasis on animal welfare. Acta Vet. Scand. 2020, 62, 22. [CrossRef]

37. Huber-Eicher, B.; Spring, P. Attitudes of swiss consumers towards meat from entire or immunocastrated boars: A representative survey. Res. Vet. Sci. 2008, 85, 625-627. [CrossRef]

38. Fredriksen, B.; Johnsen Sibeko, A.M.; Skuterud, E. Consumer attitudes toward castration of piglets and alternatives to surgical castration. Res. Vet. Sci. 2011, 90, 352-357. [CrossRef]

39. Heid, A.; Hamm, U. Consumer attitudes towards alternatives to piglet castration without pain relief in organic farming: Qualitative results from Germany. J. Agric. and Environ. Eth. 2012, 25, 687-706. [CrossRef]

40. Di Pasquale, J.; Nannoni, E.; Sardi, L.; Rubini, G.; Salvatore, R.; Bartoli, L.; Adinolfi, F.; Martelli, G. Towards the Abandonment of Surgical Castration in Pigs: How is Immunocastration Perceived by Italian Consumers? Animals 2019, 9, 198. [CrossRef] [PubMed]

41. Mancini, M.C.; Menozzi, D.; Arfini, F. Immunocastration: Economic implications for the pork supply chain and consumer perception. An assessment of existing research. Livest. Sci. 2017, 203, 10-20. [CrossRef]

42. Fishler, C. L' Homnivore. Odile Jacob, 15; Odile Jacob: Rue Soufflot, Paris, France, 2001; ISBN 978-2-7381-7599-1.

43. Bauer, R.A. Consumer behaviour as risk taking. In Risk Taking and Information Handling in Consumer Behavior; Cox, D.F., Ed.; Harvard University Press: Boston, MA, USA, 1967; pp. 23-33.

44. Cox, D.F. Risk Taking and Information Handling in Consumer Behavior; Harvard University Press: Boston, MA, USA, 1967.

45. Cunningham, S.M. The major dimensions of perceived risk. In Risk Taking and Information Handling in Consumer Behavior; Cox, D.F., Ed.; Harvard University Press: Boston, MA, USA, 1967.

46. Roselius, T. Consumer rankings of risk reduction methods. J. Mark 1971, 35, 56-61. [CrossRef]

47. Taylor, J. The role of risk in consumer behaviour. J. Mark 1974, 38, 54-60.

48. Mitchell, V.W.; Greatorex, M. Consumer risk perception in the UK wine market. Eur. J. Mark. 1988, 22, 5-15. [CrossRef]

49. Yavas, U. Out-of-country travel patterns in an Arabian Gulf country. J. Int. Mark. Mark. Res. 1992, 17, 9-18.

50. Agrawal, M. Warning labels: The role of expertise and perceived risk in pharmaceutical purchase behaviour. Health Mark. Q. 1995, 13, 99-108. [CrossRef]

51. Mitra, K.; Reiss, M.C.; Capella, L.M. An examination of perceived risk, information search and behavioral intentions in search, experience and credence services. J. Serv. Mark 1999, 13, 208-228. [CrossRef]

52. Tse, A.C.B. Factors affecting consumer perceptions of product safety. Eur. J. Mark. 1999, 33, 911-925. 
53. Verbeke, W. Beliefs, attitude and behaviour towards fresh meat revisited after the Belgian dioxin crisis. Food Qual. Prefer. 2001, 12, 489-498. [CrossRef]

54. Verbeke, W.; Viaene, J.; Guiot, O. Health Communication and Consumer Behavior on Meat in Belgium: From BSE until Dioxin. J. Health Comm. Int. Perspect. 1999, 4, 345-357. [CrossRef]

55. Da Conceição Pereira da Fonseca, M.; Salay, E. Beef, chicken and pork consumption and consumer safety and nutritional concerns in the City of Campinas, Brazil. Food Control 2008, 19, 1051-1058. [CrossRef]

56. Damico, A.B.; Aulicino, J.M.; Di Pasquale, J. Perceptions and Preconceptions about Chicken and Pork Meat: A Qualitative Exploratory Study of Argentine Consumers in the Metropolitan Area of Buenos Aires. Sustainability 2020, 12, 6729. [CrossRef]

57. Nelson, C.H. Risk perception, behavior, and consumer response to genetically modified organisms. Am. Behav. Sci. 2001, 44, 1371-1388. [CrossRef]

58. Gaskell, G.; Allum, N.; Wagner, W.; Kronberger, N.; Torgersen, H.; Hampel, J.; Bardes, J. GM Foods and the Misperception of Risk Perception. Risk Anal. 2004, 24, 185-194. [CrossRef] [PubMed]

59. Zhang, Y.; Yang, H.; Cheng, P.; Luqman, A. Predicting consumers' intention to consume poultry during an H7N9 emergency: An extension of the theory of planned behavior model. Hum. Ecol. Risk Assess. An Int. J. 2019, 26, 190-211. [CrossRef]

60. Wen, X.; Sun, S.; Li, L.; He, Q.; Tsai, F.-S. Avian Influenza-Factors Affecting Consumers' Purchase Intentions toward Poultry Products. Int. J. Environ. Res. Public Health 2019, 16, 4139. [CrossRef]

61. Yeung, R.M.W.; Morris, J. Consumer perception of food risk in chicken meat. Nutr. Food Sci. 2001, 31, $270-279$. [CrossRef]

62. Hsu, J.L.; Liu, K.E.; Huang, M.H.; Lee, H.J. Consumer Knowledge and Risk Perceptions of Avian Influenza. Poult. Sci. 2008, 87, 1526-1534. [CrossRef]

63. Setbon, M.; Raude, J.; Fischler, C.; Flahault, A. Risk Perception of the "Mad Cow Disease" in France: Determinants and Consequences. Risk Anal. 2005, 25, 813-826. [CrossRef] [PubMed]

64. Pennings, J.M.E.; Wansink, B.; Meulenberg, M.T.G. A note on modeling consumer reactions to a crisis: The case of the mad cow disease. Int. J. Res. Mark 2002, 19, 91-100. [CrossRef]

65. Myae, A.C.; Goddard, E. Household behavior with respect to meat consumption in the presence of BSE and CWD. Can. J. Agric. Econ. 2020, 1-27. [CrossRef]

66. Harvey, J.; Erdos, G.; Challinor, S.; Drew, S.; Taylor, S.; Ash, R.; Ward, S.; Gibson, C.; Scarr, C.; Dixon, F.; et al. The relationship between attitudes, demographic factors and perceived consumption of meats and other proteins in relation to the BSE crisis: A regional study in the United Kingdom. Health Risk Soc. 2001, 3, 181-197. [CrossRef]

67. Thys, S.; .Mwape, K.E.; Lefèvre, P.; Dorny, P.; Phiri, A.M.; Marcotty, T.; Phiri, I.K.; Sarah Gabriël, S. Why pigs are free-roaming: Communities' perceptions, knowledge and practices regarding pig management and taeniosis/cysticercosis in a Taenia solium endemic rural area in Eastern Zambia. Vet. Parasitol. 2016, 225, $33-42$. [CrossRef]

68. Dione, M.; Ouma, E.; Opio, F.; Kawuma, B.; Pezo, D. Qualitative analysis of the risks and practices associated with the spread of African swine fever within the smallholder pig value chains in Uganda. Prev. Vet. Med. 2016, 135, 102-112. [CrossRef]

69. McCarthy, M.; O’Reilly, S.; Cotter, L.; de Boer, M. Factors influencing consumption of pork and poultry in the Irish market. Appetite 2004, 43, 19-28. [CrossRef]

70. Kennedy, J.; Delaney, L.; Hudson, E.M.; McGloin, A.; Wall, P.G. Public perceptions of the dioxin incident in Irish pork. J. Risk Res. 2010, 13, 937-949. [CrossRef]

71. Bonneau, M. Immunocastration as an alternative to conventional castration to control boar taint in entire male pigs. In Proceedings of the 19 International Science Symposium on Nutrition of Domestic Animals' Zadravec-Erjavec Days'(19. Mednarodno znanstveno posvetovanje o prehrani domacih zivali'Zadravcevi-Erjavcevi dnevi'), Radenci, Slovenija, 11-12 November 2010.

72. Tuyttens, F.A.; Vanhonacker, F.; Verhille, B.; De Brabander, D.; Verbeke, W. Pig producer attitude towards surgical castration of piglets without anaesthesia versus alternative strategies. Res. Vet. Sci. 2012, 92, 524-530. [CrossRef] 
73. Aluwé, M.; Bonneau, M.; Buttazzoni, L.; Čandek-Potokar, M.; Courboulay, V.; Failla, S.; Fontanesi, L.; Font-i-Furnols, M.; Fredriksen, B.; Škrlep, M.; et al. Pig Castration: Methods of Anaesthesia and Analgesia for All Pigs and Other Alternatives for Pigs Used in Traditional Products. Directorate-General for Health and Food Safety Animal Welfare. 2016. Available online: https://op.europa.eu/en/publication-detail/-/ publication/5fe8db00-dbb8-11e6-ad7c-01aa75ed71a1 (accessed on 20 July 2020).

74. Linnemann, A.R.; Benner, M.; Verkerk, R.; van Boekel, M.A.J.S. Consumer driven food product development. Trends Food Sci. Technol. 2006, 17, 184-190. [CrossRef]

75. Stolzenbach, S.; Bredie, W.L.P.; Byrne, D. Consumer concepts in new product development of local foods: Traditional versus novel honeys. Food Res. Int. 2013, 52, 144-152. [CrossRef]

76. Lagerkvist, C.J.; Hess, S. A meta-analysis of consumer willingness to pay for farm animal welfare. Eur. Rev. Eur. Rev. Agric. 2011, 38, 55-78. [CrossRef]

77. Clark, B.; Stewart, G.B.; Panzone, L.A.; Kyriazakis, I.; Frewer, L.J. Citizens, consumers and farm animal welfare: A meta-analysis of willingness-to-pay studies. Food Policy 2017, 68, 112-127. [CrossRef]

78. ISTAT-National Institut of Statistic. 2018. Available online: https://www.istat.it/ (accessed on 20 July 2020).

79. Brown, M.B.; Forsythe, A.B. Robust tests for the equality of variances. J. Am. Stat. Assoc. 1974, 69, 364-367. [CrossRef]

80. Welch, B.L. The generalization of Student's problem when several different population variances are involved. Biometrika 1947, 34, 28-35. [CrossRef] [PubMed]

81. Duncan, D.B. Multiple range rests for correlated and heteroscedastic means. Biometrics 1957, 13, $164-176$. [CrossRef]

82. Scheffé, H. A method for judging all contrasts in the analysis of variance. Biometrika 1953, 40, 87-104.

83. Hill, R.C.; Griffiths, W.E.; Lim, G.C. Principles of Econometrics, 3rd ed.; Wiley: New York, NY, USA, 2008.

84. Hair, J.F.; Black, W.C.; Babin, B.J.; Anderson, R.E. Multivariate Data Analysis: A Global Perspective, 7th ed.; Pearson Education: Upper Saddle River, NJ, USA, 2010.

85. De Lillo, A.; Argentin, G.; Lucchini, M.; Sarti, S.; Terraneo, M. Multivariate Analysis for Social Sciences; Pearson Education: Milan, Italy, 2007; pp. 197-245. ISBN 978-88-7192-376-5.

86. Mancini, M.C.; Menozzi, D.; Arfini, F.; Veneziani, M. How Do Firms Use Consumer Science to Target Consumer Communication? The case of Animal Welfare. In Case Studies in the Traditional Food Sector, 1st ed.; Cavicchi, A., Santini, C., Eds.; Woodhead Publishing: Kidlington, UK, 2018; pp. 337-357.

87. Connor, M.; Cowan, S.L. Consumer evaluation of farm animal mutilations. Res. Vet. Sci. 2020, 128, 35-42. [CrossRef]

88. Adinolfi, F.; De Rosa, M. Effect of novelty on consumption behaviour: Theoretical considerations and empirical verifications of food products. REA 2002, 4, 733-758.

89. Bianchi, M. Novelty, preference, and Fashion: When goods are insettling. J. Econ. Behav. Organ. 2002, 47, 1-18. [CrossRef]

90. La Lama, G.M.D.; Estévez-Moreno, L.X.; Sepulveda, W.; Estrada-Chavero, M.; Rayas-Amor, A.A.; Villarroel, M.; María, G.; Miranda-De-La-Lama, G. Mexican consumers' perceptions and attitudes towards farm animal welfare and willingness to pay for welfare friendly meat products. Meat Sci. 2017, 125, 106-113. [CrossRef] [PubMed]

91. Tomasevic, I.; Bahelka, I.; Čítek, J.; Čandek-Potokar, M.; Djekić, I.; Getya, A.; Guerrero, L.; Ivanova, S.; Kušec, G.; Nakov, D.; et al. Attitudes and beliefs of Eastern European Consumers Towards Animal Welfare. Animals 2020, 10, 1220. [CrossRef] [PubMed]

92. EC. Attitudes of Europeans towards Animal Welfare. Special Eurobarometer, 442 Wave EB 84.4. EU Publications: Brussels, Belgium, 2016. Available online: https:/ec.europa.eu/commfrontoffice/publicopinion/ index.cfm/ResultDoc/download/DocumentKy/71348 (accessed on 20 July 2020).

(C) 2020 by the authors. Licensee MDPI, Basel, Switzerland. This article is an open access article distributed under the terms and conditions of the Creative Commons Attribution (CC BY) license (http://creativecommons.org/licenses/by/4.0/). 